\title{
Kinetic modeling of ethanol production by batch fermentation of sugarcane juice using immobilized yeast
}

\author{
Kingsley Chidozie Agu and Mujeeb Koyejo Oduola * \\ Chemical Engineering Department, University of Port Harcourt, Nigeria. \\ Global Journal of Engineering and Technology Advances, 2021, 07(01), 124-136 \\ Publication history: Received on 01 March 2021; revised on 19 April 2021; accepted on 21 April 2021
}

Article DOI: https://doi.org/10.30574/gjeta.2021.7.1.0060

\begin{abstract}
Ethanol production via the batch fermentation of sugarcane juice using immobilized yeast has been studied. The influence of glucose concentration, ethanol concentration, and cell concentration (biomass) on the process rate throughout the period of fermentation has been investigated. Initial cell concentration was found to be $4.60 \mathrm{~g} / \mathrm{L}$ saccharomyces cerevisiae. Biomass, ethanol and glucose concentrations were measured at different time interval during fermentation. The experimental data obtained were fitted using a variety of models for yeast growth. The logistic model gave the best fitting and was the basis for the development of the overall kinetic model. For ethanol formation, different model based on the logistic model for yeast growth were used to fit the experimental data and the leudeking - piret model was adopted because of its good fit. The leudeking - piret model was also adopted for substrate consumption. The estimated values of the kinetic parameters in the developed model were $\mu_{\mathrm{m}}=0.04216 \mathrm{hr}^{-1}, \mathrm{X}_{\mathrm{m}}=6.2652 \mathrm{~g} / \mathrm{L}, \alpha=$ $24.87149 \mathrm{~g} / \mathrm{g} . \mathrm{hr}, \mathrm{Yx} / \mathrm{s}=0.18292 \mathrm{~g} / \mathrm{g}$ and $\mathrm{m}=0.008171 \mathrm{~g} / \mathrm{g} . \mathrm{hr}$. Therefore, a model based on the logistic equation of yeast growth, growth associated production of ethanol, and consumption of glucose for biomass and maintenance was found to accurately fit the production of ethanol from sugarcane.
\end{abstract}

Keywords: kinetic modelling, ethanol, fermentation, sugarcane, yeast.

\section{Introduction}

The ever increasing demand for ethanol and ethanol-based products over the years has necessitated an imminent requirement for high yielding production strains and search for alternative economically viable production processes. This is aggravated by the concerns about the various economic and environmental effects of depletion of nonrenewable fossil fuel sources, which places bioethanol as a suitable alternative to petroleum $[1,2,3]$.

Ethanol is gradually and increasingly gaining importance in our society and the world at large. Ethanol is a very important component used in the pharmaceuticals. It is also used in some part of the world (Brazil) as a major component in the production of gasohol (alcohol and gasoline). In Nigeria, ethanol is used in the production of perfumes and vinegar. It is also used as beverage in occasions like burial ceremonies, marriages and other traditional events $[4,5,6]$.

Sugarcane is normally used for sugar production. Sugarcane juice is a preferred drink in India, especially in summer. However, disease and insect infested canes or shriveled and rotten canes have to be separated from the healthy canes for processing. Thus, the juice from such unwanted canes could be used for ethanol production, which could be used as bio-fuel to supplement the energy needs of the country. Sugarcane ethanol is an alcohol-based fuel produced by the fermentation of sugarcane juice and molasses. Because it is a clean, affordable and low-carbon biofuel, sugarcane ethanol has emerged as a leading renewable fuel for the transportation sector [7].

\footnotetext{
* Corresponding author: Koyejo Oduola

Department of Chemical Engineering, University of Port Harcourt, Nigeria. 
Rum is defined as any alcoholic distillate from the fermented juice of cane syrup, sugarcane molasses or other sugarcane derivative, distilled at less than $190^{\circ}$ proof (whether or not such proof is further reduced prior to bottling to no less than $80^{\circ}$ proof) in such a manner that the distillate possesses the taste, aroma and characteristics generally attributed to rum and includes mixtures solely of such distillates [8]. Rum production is centered in the West Indies. Traditional rum making countries are Jamaica, Martinique, Puerto Rico, Cuba, Barbados, Trinidad, Haiti, Guadeloupe, the Virgin Islands, the Dominican Republic, and Guyana. Other rum producing countries include Brazil, Peru, Mexico and parts of Asia and Africa [9]. Rum can be used for direct consumption in a pure form or as mixed drinks [8]. It can also be used as a flavoring agent in chocolates, liquors and in tobacco (cigars) and bakery products.

Literature has shown that the sugarcane is the basic raw material for rum production. The types of raw material used, the method of clarification, fermentation conditions (rum yeast), distillation conditions, and aging conditions will affect the aroma of the final rum product. Different breeding and selection techniques have been applied to sugarcane to improve sugar yield. Selections have been made based upon cane yield, sugar content, fiber content, habit, disease resistance, insect resistance, and other characteristics such as flowering, spines, brittleness, and herbicide tolerance Sugarcane is a perennial tropical grass that produces unbranched stalks. It consists of root, stalk (with nodes), flower, and leaves [10]. Its stalks can be 3-4 $\mathrm{m}$ tall and $5 \mathrm{~cm}$ in diameter. Sugar is extracted from these stalks of cane, and it is contained in the fibro-vascular bundles. The composition of sugarcane (Saccharum officinarum L.) varies depending on such factors as variety, soil condition, climate, and use of fertilizers [7, 8]. Sugar extraction is achieved after crushing the mat of sugarcane in a mill tandem of multiples stages. Addition of water during milling improves the efficiency of the sugar extraction. The extraction efficiency of modern mills is about 92-96\%. Higher extractions will result in the extraction of more non-sugar components that will have to be removed later on.

Fermentation is a chemical process involving the use of microbial metabolic process in which carbohydrates and other nutrients are oxidized partially to a variety of breakdown products such as alcohol, acids, amino acids, other metabolites and antibiotics and a small amount of energy. Fermentation is carried out for so many reasons which production of alcohol is one of them. Fermentation is carried out in fermenters using micro-organisms such as yeast in the case of beer fermentation and wine production.

Yeast belong to the family of "Sacchoromyce" and there are three prominent species in the yeast family , they are; Sacchoromyces Uvanum, Sacchoromyces Carsbergensis and Sacchoromyces Cervisae [11]. By fermentation, the yeast species Saccharomyces cerevisiae converts carbohydrates to carbon dioxide and alcohols - for thousands of years the carbon dioxide has been used in baking and the alcohol in alcoholic beverages [12]. To propagate the yeast, certain mass of yeast say $4.5 \mathrm{Kg}$ is added to some quantity of the fermentable filtrate at very low temperature or moderately low temperature say $20-100^{\circ} \mathrm{C}$.

The yeast regenerates by budding process which is an asexual reproductive method [13]. During budding the carbohydrate and proteinous nutrient found in the filtrate are utilized such that the yeast grows and enable in size by cell growth. This involves the mother cell of the yeast growing an offspring and this offspring protrude from the side of the mother yeast cell body which could be unilateral or multilateral. Once budding takes place in a point. A scar will remain on the cell wall and so further repeat the process on other points; therefore about 28-30 scars can occur on the mother yeast body. Thus the process of regeneration of yeas continues so long as the medium of propagation is nourished with the nutrients as well as temperature being maintained.

Fermentation is affected by several factors including the temperature, salt concentration, $\mathrm{pH}$, oxygen availability and nutrient availability. The rate of fermentation can be controlled by manipulating any of the factors. Despite its complexity, the rate of fermentation is largely dependent upon three basic parameters namely wort composition (i.e. fermentable filtrates normally nutrients for the yeast), the yeast and processing conditions such as time, temperature, volume, vessel shape and size - pH and degree of reaction are also very important variables.

However, these conditions are in general applied to all classes of fermentation, be it batch process or the continuous processes. In this process, fermentation can exist as lager (bottom) and Ale (top) fermentation. A viable yeast species is recommend for fermentation processes and yeast viability of not less than $80 \%$ is acceptable on the utilization of a less viable yeast, the rate of fermentation would be grossly affected and reduced. The reaction is that less viable yeast or unhealthy yeast normally undergoes an incomplete biochemical metabolism leading to the production of undesirable substances such as methanol, acetone and acetaldehydes etc. [12].

Another important factor in fermentation process is the process temperature, being that the activation of yeast is enhanced with the temperature levels. For bottom (lager) fermentation, yeast fermentation normally takes place at temperature of about $8-11^{\circ} \mathrm{C}$. But Ale (top) fermentation normally takes place at about $15-18^{\circ} \mathrm{C}$. Also fermentation 
could also take place at temperatures of about $25-28^{\circ} \mathrm{C}$ and this is normally referred to as accelerated fermentation processes. Different bacteria tolerate different temperatures. Most have an optimum of between 20-30oC although some prefer higher temperatures $\left(50-55^{\circ} \mathrm{C}\right)$ and others colder $\left(15-20^{\circ} \mathrm{C}\right)$. Most lactic acid bacteria work best at temperatures of $18-220 \mathrm{C}$. The Leuconostoc species which initiate fermentation have an optimum of $18-22^{\circ} \mathrm{C}$. The Lactobacillus species have temperature optima above $22^{\circ} \mathrm{C}$. The optimum temperature for pickle fermentation is around $21^{\circ} \mathrm{C}$ [14].

The acidity and alkalinity levels of the fermentation extract (the $\mathrm{pH}$ factor) is another factor worthy of note. A pH of 3.0 to 3.5 is recommended for a fermentable extract and when it is higher than this; organic acids (i.e. lactice acids) needed to be added. Also the yeast solution needs to be acidic and a $\mathrm{pH}$ of 4.5 to 5.0 is also recommended. The optimum pH for most bacteria is near the neutral point ( $\mathrm{pH}$ 7.0). Certain bacteria are acid tolerant and will survive at reduced pH levels. Both Lactobacillus and Streptococcus species are acid tolerant. The essence of keeping the yeast solution or the fermentable extract in acid medium is to keep the process devoid of harmful bacteria and undesirable microbes that could lead to offensive odor and taste [14].

Some of the fermenters are anaerobes while others require oxygen. Some of the lactobacilli are microaerophilic which means they grow in the presence of reduced amounts of oxygen. All bacteria however require a source of nutrients for metabolism. The fermenters require carbohydrates, either simple sugars such as glucose and fructose or complex ones such as starch or cellulose. The energy requirements of microbes are very high. Limiting the amount of substrate available can reduce the rate of fermentation [15]

Lactic acid bacteria tolerate high salt concentrations, which gives them an advantage over other less tolerant species. This allows the lactic acid fermenters to begin metabolism, which produces acid, which then further inhibits the growth of non-desirable organisms. Leuconostoc species tolerate high salt concentrations, which makes them ideal to start the lactic acid fermentation [14].

Salt plays an important role in initiating the fermentation and also in the quality of the product. The addition of too much salt may inhibit the desirable bacteria and also affect the hardness of the product. The principle function of salt is to withdraw juice from the vegetables and make a favorable environment for fermentation. Salt is generally added to give a final concentration of 2.0-2.5\%. At this concentration the Lactobacilli are slightly inhibited but the Leuconostoc are not affected [14]. Industries that specifically carry out fermentation are the food processing and pharmaceutical industries [16].

The attachment /adsorption of the cells is believed to be time dependent due to the interaction between long-range attractive forces (van der Waals and electrostatic forces). Mauricio et al [5] have revealed that the ethanol fermentation was faster with cells immobilized in Ca-alginate compared to the fermentation with cells immobilized in PVA (polyvinyl alcohol) gel. Under the same experimental conditions, higher cell densities and ethanol concentrations were attained in the fermentation performed by alginate immobilized yeast relative to the fermentation by PVA immobilized yeast.

Amenaghawon et al [3] upon investigating the 'Kinetic Modelling of Ethanol Inhibition during Alcohol fermentation of Corn Stover using Saccharomyces Cerevisiae', discovered that a linear relationship exists between relative specific growth rate and ethanol concentration. A linear relationship also exists between specific ethanol productivity rate and ethanol concentration. Zeynep Balci et al. [17] used yeast cells as a model for whole cell immobilization in several conducting polymer matrices and the invertase activity of the immobilized cells were investigated. The immobilized cell system showed comparable kinetic data with that of the immobilized enzyme. The study also showed that it is worth using immobilized yeast cells instead of immobilized invertase. Mayuri et al. [18] studied the growth kinetics of Sacchoromyce.cerevisiae (brewer's yeast) for sugar cane wine production. The specific growth rate and generation time for fermentation on sugar cane juice were found to be $0.772 \mathrm{~h}^{-1}$ and $0.89 \mathrm{~h}^{-1}$. The study proved that Sacchoromyce cerevisiae can be used effectively for production of sugar cane wine.

According to the work on immobilized microbial cells by Durand and Navano [19], immobilized cells can be effectively used in continuous processes when compared to free cells. Based on the advantages of immobilized cells over immobilized enzymes, redox reactions are possible.

This study is therefore centered on the fermentation of the sugarcane juice which should cover the sugar content, amount of oxygen, nature and taste of product at the various stages of the fermentation process. This shows that this study is not just for the fermentation process only, but the use of immobilized yeast cell in the fermentation process which in turn increases the yield. 


\section{Methodology}

\subsection{Experimental Procedures}

The experimental procedures are divided into three basic stages. They include:

1. Immobilization stage

2. Extraction stage

3. Fermentation stage

The major precaution to be taken in the course of carrying this experiment is the maintenance of $100 \%$ sterility, to ensure that, all equipment must be sterilized by subjecting them to high temperature over a period of time $\left(121^{\circ} \mathrm{C}\right.$ for 15mins). This will eliminate any external microbe on any of the equipment.

\subsubsection{Immobilization Stage}

This is the first stage of the experiment. Here, the yeast cells are immobilized using sodium alginate. Below are the steps involved in this stage:

- Mix the dried yeast with $25 \mathrm{~mL}$ of sugar solution in a small beaker. Cover and leave to rehydrate for $10 \mathrm{minutes}$ at room temperature.

- Add $25 \mathrm{ml}$ of sodium alginate solution to the yeast suspension. Stir well.

- Draw up some of the yeast/alginate mixture into a syringe. Add it, a drop at a time, to the calcium chloride solution.

- Leave the immobilized yeast cell beads to harden in the calcium chloride solution for 5-10 minutes. The alginate will be ionically cross-linked by the calcium ions.

- Separate the beads from the solution using the tea strainer.

- $\quad$ Place the beads in a sugar solution in a conical flask.

At the end of this first stage, the yeast has been immobilized waiting to be charged into the fermentation vessel/tank to aid fermentation.

\subsubsection{Extraction Stage}

This stage of the experiment deals with the extraction of sugarcane juice from sugarcane. For the purpose of the third or final stage of this practical work, $700 \mathrm{ml}$ of sugarcane juice is to be extracted from the sugarcane stems. Below are the steps involved in this stage:

- Harvest fresh sugarcane stems (one can also buy newly harvested sugarcane stems from farmers).

- Wash thoroughly with warm water (at $80^{\circ} \mathrm{C}$ ).

- Peel the sugarcane stems to remove the hard cover and expose the main cane.

- Wash again using warm water to avoid contamination.

- Cut the washed stems into smaller pieces for easy grinding.

- Grind the sugarcane pieces to get a mixture of the juice and the fibres.

- Add warm water (at $80^{\circ} \mathrm{C}$ ) into the mixture and allow for $2 \mathrm{hrs}$.

- Using the white handkerchiefs as the sieve, sieve out the sugarcane fibres, the resulting liquid is known as the sugarcane juice.

- The juice is subjected to a temperature of $60^{\circ} \mathrm{C}$, this temperature is maintained for $60 \mathrm{mins}$ to attain full pasteurization, this is to eliminate any foreign microbe that must have been introduced during the extraction process

The final stage starts immediately the extraction process has been completed to avoid microbial actions on the juice before fermentation.

\subsubsection{Fermentation Stage}

This is the final stage of the practical work which lasted for 4 days. Below are the steps involved in this stage:

- The extracted sugarcane juice and the immobilized yeast are charged into the fermenter, this marks the beginning of the fermentation process. This culture will be maintained at a temperature range of $25^{\circ} \mathrm{C}-30^{\circ} \mathrm{C}$ for the $4 \mathrm{days}$ (96hrs) 
- At $\mathrm{t}=0$, the initial biomass concentration, ethanol concentration and glucose concentration were recorded.

- Samples were withdrawn at $12 \mathrm{hrs}$ interval to analyze the biomass concentration, ethanol concentration and glucose concentration. The bricks meter is used to check the sugar content of the culture. The values at each point should be recorded, this will continue till the end of the 4 days after which the sugarcane juice must have turned into alcohol.

For accuracy, these samples were analyzed using a sophisticated laboratory using the gas liquid chromatographic method.

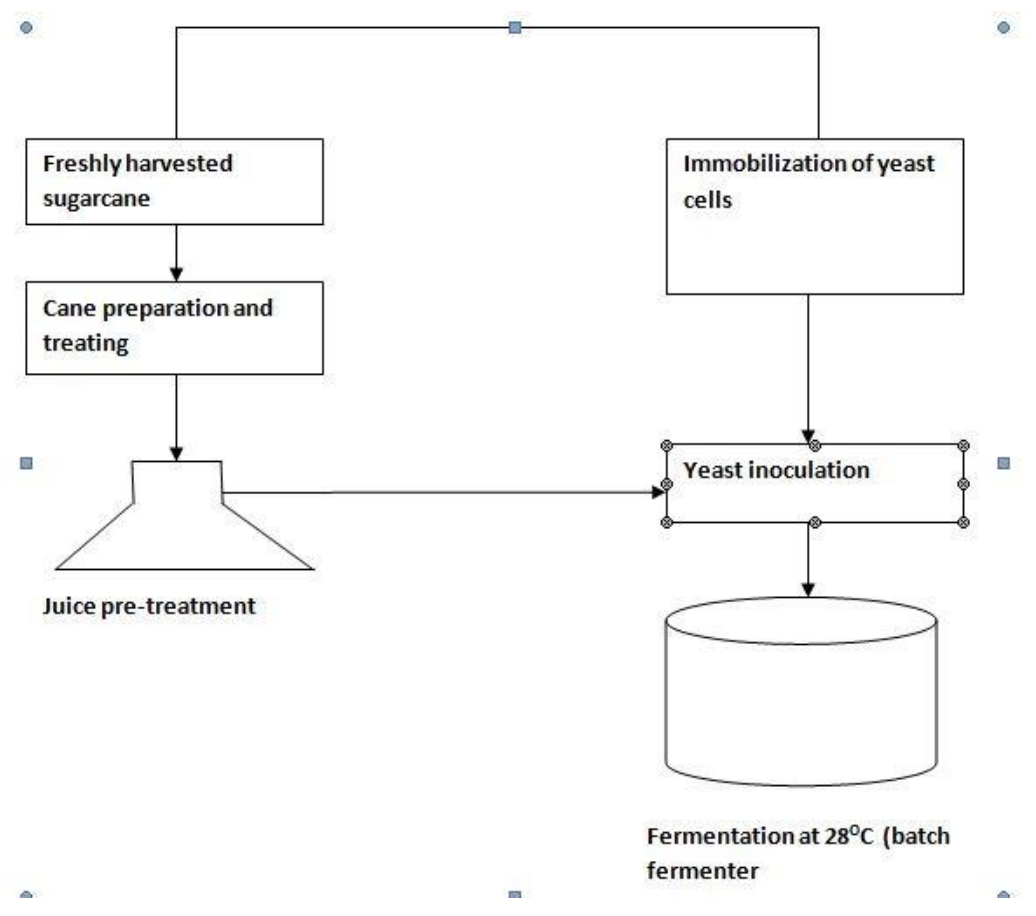

Figure 1 Diagrammatic Illustration of the Fermentation Process

\subsection{Kinetic models for the fermentation process}

In the design of any chemical, or biochemical, process one must consider two more or less distinct aspects. First, there are the chemical reactions themselves and secondly, the numerous physical processes which accompany and follow them. Some of these physical processes are quite clearly separate, like the purification of raw materials and products. Others, like the transport of materials to and from the surface of a solid catalyst, are intimately bound up with the reactions themselves (Elmer L. Gaden, 2000).

Fermentation process consists of the following biochemical reactions;

$\mathrm{C}_{6} \mathrm{H}_{12} \mathrm{O}_{6} \longrightarrow \mathrm{K}_{1} \longrightarrow \quad 2 \mathrm{CH}_{3} \mathrm{COOH}+\mathrm{NADH}_{2}$

glucose Pyruvic acid

$2 \mathrm{CH}_{3} \mathrm{COCOOH} \longrightarrow 2 \mathrm{~K}_{2} \longrightarrow 2 \mathrm{CH}_{3} \mathrm{CHO}$

$2 \mathrm{CH}_{3} \mathrm{CHO} \underset{\mathrm{K}}{\stackrel{2 \mathrm{NADH}_{2}}{\longrightarrow}} \quad \begin{aligned} & \text { Acetaldehyde } \\ & 2 \mathrm{CH}_{3} \mathrm{CH}_{2} \mathrm{OH}+2 \mathrm{NAD}\end{aligned}$

The overall chemical reaction for the fermentation process is given as

$\mathrm{C}_{6} \mathrm{H}_{12} \mathrm{O}_{6}+2 \mathrm{ADP}+2 \mathrm{PO}_{4}{ }^{3-} \longrightarrow \mathrm{K}_{4} \longrightarrow 2 \mathrm{C}_{2} \mathrm{H}_{5} \mathrm{OH}+2 \mathrm{CO}_{2}+2 \mathrm{ATP}$ 
The above biochemical reaction is however a shortcut of the original glycolytic pathway which may be complex as has been given earlier. Therefore the summary of the biochemical reaction for fermentation is the case of the glucose being converted to pyruvic acid and from pyruvic acid to acetaldehyale and finally to ethanol.

The rate equation for any chemical reaction depends on the concentration of the reactants and products of the reactions. It is also a factor of the rate constant as well as the reactants and products. The overall reaction for the ethanol fermentation from simple sugars may be written as

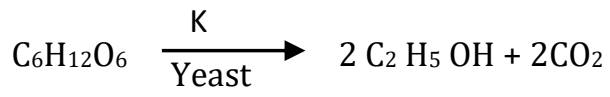

Since it is not known that this reaction is elementary, the rate can be written in the power law rate form as;

$$
\mathrm{r} \quad \mathrm{K}\left[\mathrm{C}_{6} \mathrm{H}_{12} \mathrm{O}_{6}\right]^{\mathrm{n}} \text { or } \quad \mathrm{r}=\mathrm{K}\left[\mathrm{C}_{2} \mathrm{H}_{5} \mathrm{OH}\right]^{\mathrm{n}}
$$

Where:

$n$ is the order of reaction; $r$ the rate of fermentation; $k$ is rate constant ; and [ $\left.\mathrm{C}_{6} \mathrm{H}_{12} \mathrm{O}_{6}\right],\left[\mathrm{C}_{2} \mathrm{H}_{5} \mathrm{OH}\right]$ is the concentration of glucose or ethanol product respectively.

The use of kinetic models to describe the behaviour of biological systems has been acknowledged to be important because it can reduce the number of experiments needed to eliminate extreme possibilities and provide mathematical expressions that can quantitatively describe the mechanism of the process as required for optimization and control.

These are mathematical expressions or empirical relations formulated based on the principles of basic science and engineering concept. And can be found to validate experimental determined results. Some of these rate expressions are too complex to be very useful for reactor design volume.

\subsubsection{Logistic model}

Under optimal growth conditions and when the substrate and product inhibition play no role (not effective), the rate of biomass concentration is given by

$$
\frac{d X}{d t}=\mu_{m} X
$$

Where $\mu_{m}$ is the maximum specific growth with respect to the fermentation conditions. The above equation also known as unstructured Malthus model equation implies that X increases with time regardless of the substrate availability. The Riccati equation form of the model is given as

$$
\frac{d X}{d t}=\mu_{m} X\left[1-\frac{X}{X_{m}}\right]
$$

Where $X_{m}$ is the maximum biomass concentration in $\mathrm{g} / \mathrm{l}$. with the initial condition, $\mathrm{X}=\mathrm{X}_{0}$ at $\mathrm{t}=0$, equation (8) can be integrated to give the logistic equation which may represent both exponential and stationary phase. The resulting logistic equation is given below

$$
X=\frac{X_{0} X_{m} e^{\mu_{m} t}}{X_{m}-X_{0}+X_{0} e^{\mu_{m} t}}
$$

Since the batch culture is a closed system, it maintains cell viability for a short while.

\subsubsection{Leudeking-Piret model}

The Leudeking-Piret model [20] states that the product formation rate varies linearly with both the instantaneous cell mass concentration $(\mathrm{X})$ and growth rate $\left(\frac{d X}{d t}\right)$ as:

$$
\frac{d p}{d t}=\alpha \frac{d X}{d t}+\beta X
$$


Where $\alpha$ and $\beta$ are empirical constants that may vary with fermentation conditions. The simplified form of this model is given as

$$
P=K+\alpha\left[\frac{X_{0} X_{m} e^{\mu_{m} t}}{X_{m}-X_{0}+X_{0} e^{\mu_{m} t}}\right]
$$

\subsubsection{Models for substrate consumption}

In the substrate consumption rate, the equation below represents the substrate consumption in the formation of biomass and biomass maintenance.

$$
-\frac{d S}{d t}=\frac{1}{Y_{\frac{x}{s}}} \cdot \frac{d X}{d t}+m \cdot X
$$

Where $Y_{\frac{x}{s}}$ the yield coefficient of biomass on substrate and $\mathrm{m}$ is is the maintenanace. For simplification purposes equations (10) and (11) were combined to give

$$
S=S 0-\frac{1}{Y_{\frac{x}{S}}}\left[\frac{X_{0} X_{m} e^{\mu_{m} t}}{X_{m}-X_{0}+X_{0} e^{\mu_{m} t}}-X_{0}\right]-X_{m} \operatorname{mln}\left[\frac{X_{m}-X_{0}+X_{0} e^{\mu_{m} t}}{X_{m}}\right]
$$

The equation above is known as leudeking-piret substrate consumption

\subsubsection{Michaelis - Menten rate equation and the Lineweaver - Burk Plot}

The Michaelis - Menten rate equation and the lineweaver - Burk plot have been proposed rate expressions for ethanol fermentation [21]. For the Michaelis - Menten proposition for ethanol fermentation, we have

$$
V=\frac{V_{\max } S}{K_{m}+S}
$$

Here, $V_{\max }$ represents the maximum rate achieved by the system, at maximum (saturating) substrate concentrations. The Michaelis constant $K_{\mathrm{m}}$ is the substrate concentration at which the reaction rate is half of $V_{\text {max. }}$. Biochemical reactions involving a single substrate are often assumed to follow Michaelis-Menten kinetics, without regard to the model's underlying assumptions [22]. The Michealis - Menten equation is not well suited for estimation of the Kinetic Parameters Vmax and Km. It is quite difficult to obtain Vmax accurately from a plot of V against S. By the following rearrangement of equation (14) the following options for data plotting and graphical parameters evaluation to accurate estimation of Vmax and Km are possible; which is known as the lineweaver-burk model plot [23]:

$$
\frac{1}{v}=\frac{1}{v_{\max }}+\frac{K_{M}}{v_{\max }} \cdot \frac{1}{S}
$$

An expression used to describe the dependence of growth rate on the concentration of the carbon source is the Monod relationship [3]. This is presented as

$$
\mu=\frac{\mu_{m} S}{k_{s}+S}
$$

Where: $\mu$ and $\mu_{\mathrm{m}}$ are the specific growth rates and maximum value respectively, $\left(\mathrm{hr}^{-1}\right)$; $\mathrm{S}$ is substrate concentration (g / I) and $K_{s}$ is the value of the substrate concentration at $\mu=0.5 \mu \mathrm{m}$ and is called the saturation constant.

The Monod Model relating limiting substrate to the specific growth rate of the yeast is only applicable where the presence of toxic metabolic products plays no role. During the course of an alcohol fermentation process, ethanol accumulates in the broth to such an extent that the metabolic activity of microorganisms is suppressed [24]. Since the presence of ethanol decreases the value of the specific growth rate, the Monod equation must be extended to include the ethanol concentration, $\mathrm{P}$ : 


$$
\text { i.e. } \quad \mu=F(S, P)
$$

Experimental works show that the inhibition of ethanol affects only $\mu_{\mathrm{m}}$ and not Ks which means that the inhibition is not competitive. This modifies the specific growth rate to

$$
\mu=\mu_{1} \mathrm{~S} / \mathrm{Ks}+\mathrm{S}
$$

Where $\mu_{1}=$ is the value of the maximum specific growth rate in the presence of ethanol. When ethanol plays no role $\mu_{1}$ approaches $\mu_{0}$. Four types of dependence of $\mu \mathrm{i}$ on the ethanol concentration have been reported in literature [24].

\section{Results and discussion}

The data obtained from the experiment were analyzed different models. The biomass versus time data were analyzed using logistic model, the glucose versus time data were analyzed using leudeking-piret model for substrate consumption and the ethanol versus time data were analyzed using the product formation model proposed by leudeking and piret. The root mean square values derived from this analysis using datafit was compared the ones obtained from Microsoft excel regression analysis. Following the comparison, useful conclusions have been drawn.

\subsection{Yeast growth kinetics}

In the kinetics of yeast, the biomass concentration values against time values were considered. The initial cell concentration was $4.60 \mathrm{~g} / \mathrm{l}$ and the maximum cell concentration was $6.2652 \mathrm{~g} / \mathrm{l}$. by fitting the experimental data for cell growth into the logistic equation, the correlation coefficients (root mean square value) obtained was 0.9743 (Table 1). The regression analysis of the same data was also analyzed using Microsoft excel data analysis and the root mean square value was estimated to be 0.8270 . Therefore, both equations perfectly fitted the yeast growth but the logistic equation was the best because of the closeness of its value to unity when compared to the excel analysis. Since the logistic model gave the best fitting, it was adopted as the developed model for yeast growth. Based on the logistic model, the maximum specific growth rate $(\mu)=0.04216 \mathrm{hr}^{-1}$ for yeast growth.

Table 1 Regression data summary on the data fitting of biomass against time using logistic equation

\begin{tabular}{|l|l|l|l|}
\hline Model Identity & Logistic Model & \\
\hline Observations & 9 & & \\
\hline Model equation & $X=\frac{X_{0} X_{m} e^{\mu_{m} t}}{X_{m}-X_{0}+X_{0} e^{\mu_{m} t}}$ & & \\
\hline $\begin{array}{l}\text { Coefficient of multiple } \\
\text { determination (R-squared } \\
\text { value) }\end{array}$ & 0.974286 (estimated) & $\begin{array}{l}\text { Regression } \\
\text { Statistics }\end{array}$ & 0.909414629 \\
\hline Adjusted (R-squared value) & 0.971072 (estimated) & Multiple R & 0.827034968 \\
\hline Xo (initial cell concentration) & $4.6 \mathrm{~g} / \mathrm{l}$ (experimental) & R Square & 0.802325678 \\
\hline Standard error (maximum cell & 0.09907 (estimated) & Adjusted R Square & 0.274685994 \\
\hline $\begin{array}{l}\text { Xm } \\
\text { concentration) }\end{array}$ & Standard Error & \\
\hline Maximum specific gravity, $\mu_{\mathrm{m}}$ & $0.04216 \mathrm{hr}^{-1}$ & & \\
\hline
\end{tabular}

\subsection{Ethanol Production Kinetics}

The experimental data for ethanol production was fitted with growth associated product model and product with Lag Time Model for Ethanol Formation. The correlation coefficients (R-square) were, 0.98349 and 0.91125 for the fits respectively. Growth associated product model gave the best fit for the production of ethanol Based on the adopted model, the values of the estimated parameter was $\alpha=24.87149 \mathrm{~g} / \mathrm{g} \mathrm{hr}$ and $\mathrm{k}=-105.80134 \mathrm{hr}^{-1}$. The correlation coefficients R-square and adjusted R-square are 0.98349 and 0.98113 respectively (Table 2). This means that the growth associated product model fitted the production of ethanol very well. The value of $24.87149 \mathrm{~g} / \mathrm{g}$.hr compares well with the value of $\mathrm{a}=23.64 \mathrm{~g} / \mathrm{g} . \mathrm{hr}$ obtained by Oghome and Kamalu [25]. 


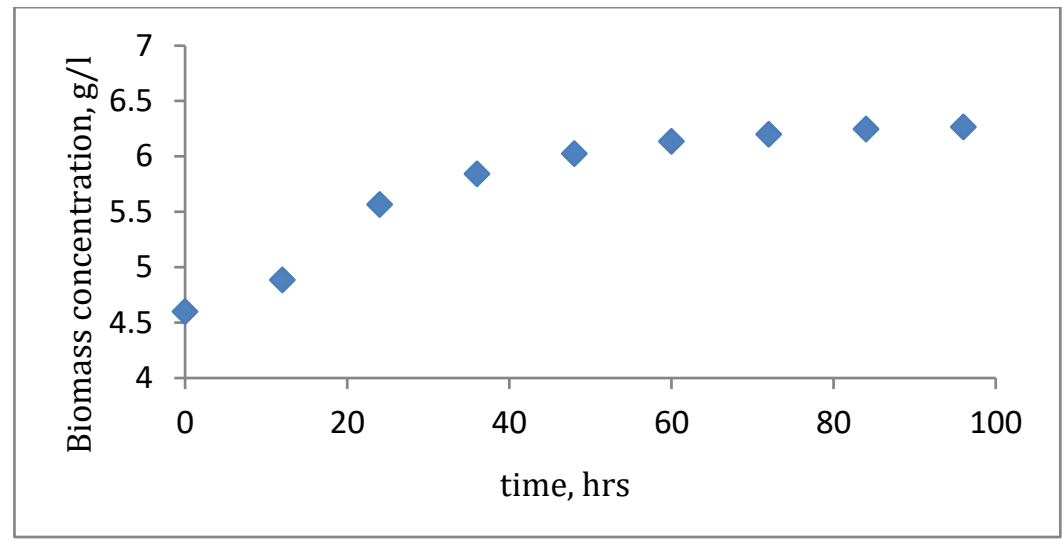

Figure 2 Variation of biomass concentration $(\mathrm{g} / \mathrm{l})$ with time $(\mathrm{hr})$.

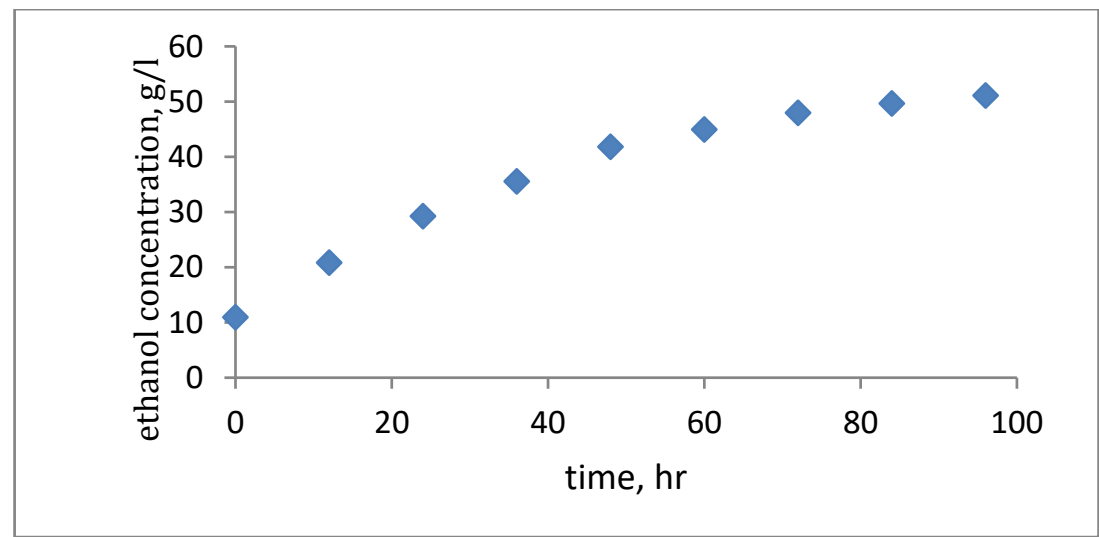

Figure 3 Variation of ethanol concentration (g/l) with time (hr).

\subsection{Substrate consumption kinetics}

Luedeking Piret model for substrate consumption was used for substrate consumption. The experimental data for glucose consumption was fitted into it, the values of the estimated parameters are $Y x / \mathrm{s}=0.18292 \mathrm{~g} / \mathrm{g}$ and $\mathrm{m}=0.008171$ g/g.hr. The correlation coefficients, R-square and adjusted R-square, are 0.98617 and 0.98420 respectively which indicates that this model fits the experimental data very well. There was a close agreement between the experiment concentration and simulated concentration for biomass, glucose and product based on Logistic, Leudeking-Piret and growth associated model respectively.

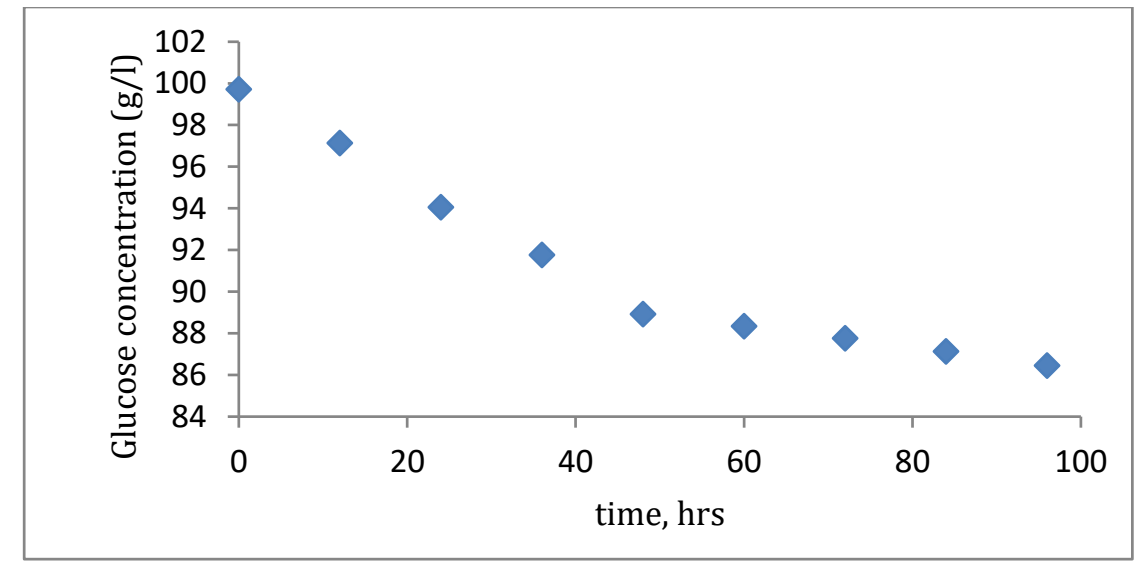

Figure 4 Variation of glucose concentration (g/l) with time (hr). 


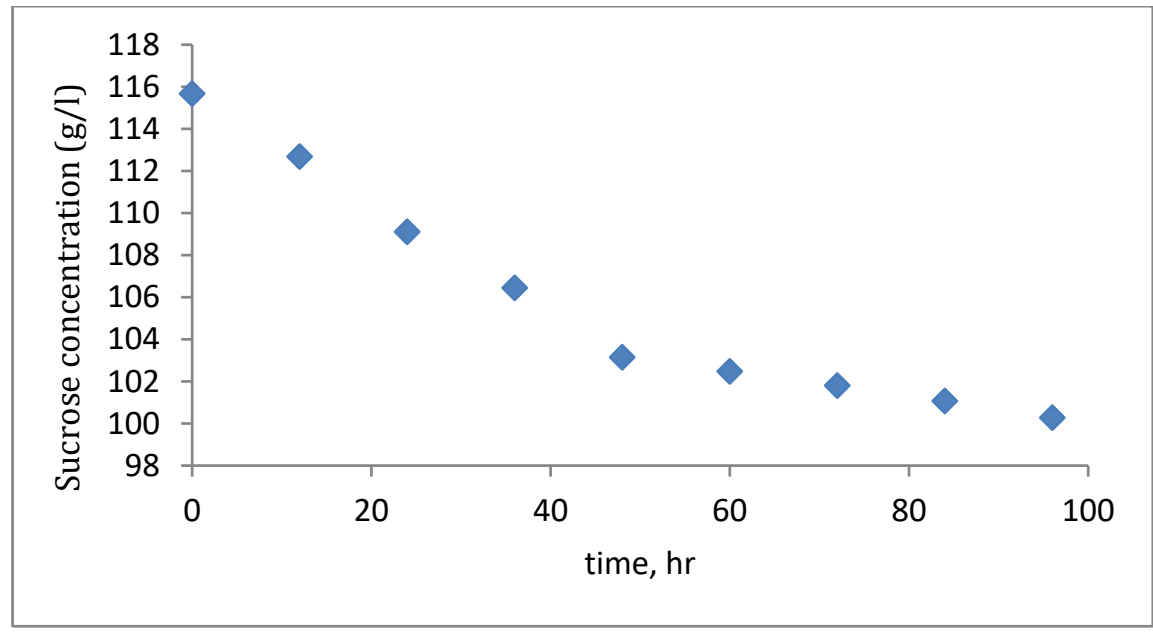

Figure 5 Variation of sucrose concentration (g/l) with time (hr).

Table 2 Parameters for growth associated product formation model - for ethanol formation

\begin{tabular}{|l|l|}
\hline Model equation & $P=K+\alpha\left[\frac{X_{0} X_{m} e^{\mu_{m} t}}{X_{m}-X_{0}+X_{0} e^{\mu_{m} t}}\right]$ \\
\hline $\mathrm{R}^{2}$ & 0.98349 (ESTIMATED) \\
& \\
\hline adjusted R & 0.98113 (ESTIMATED) \\
\hline$\alpha$ (g/ghr) & 24.87149 \\
\hline $\mathrm{k}(\mathrm{hr}-1)$ & -105.80934 \\
\hline
\end{tabular}

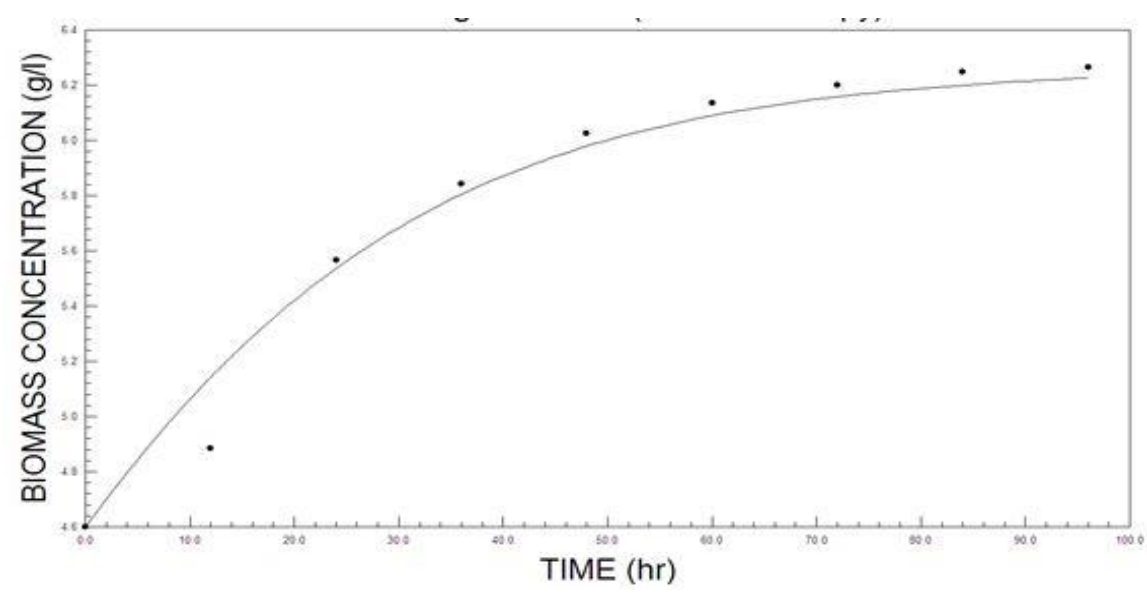

Figure 6 Plot of experimented and simulated data for the decrease of glucose with time using Leudeking-Piret model for substrate consumption. 


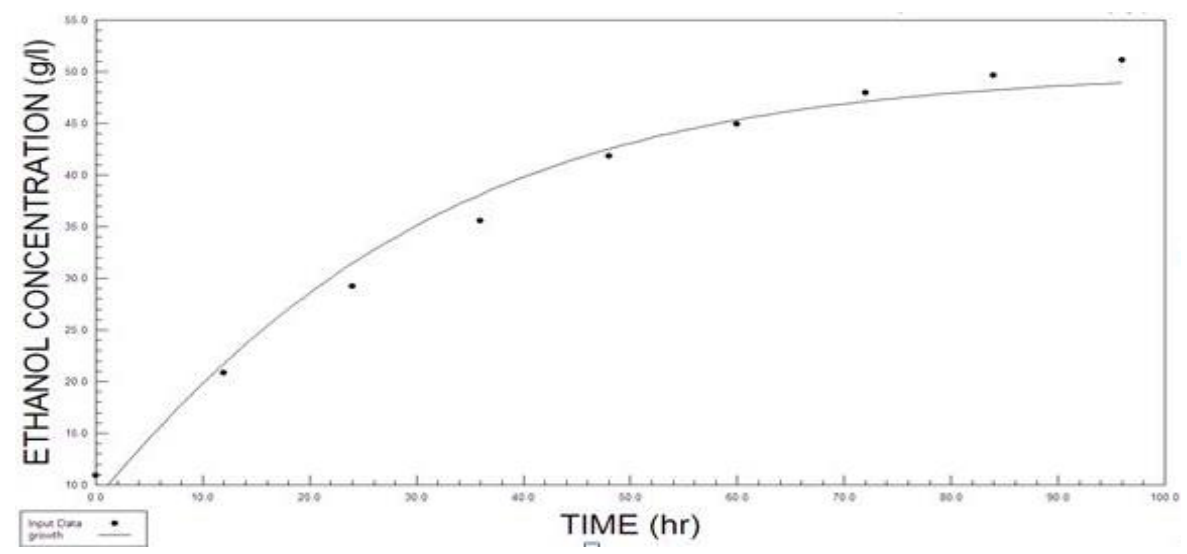

Figure 7 Plot of experimented and simulated data for the decrease of glucose with time using Leudeking-Piret model for substrate consumption.

Table 3 Parameters for product with Lag time model - for ethanol formation and substrate consumption

\begin{tabular}{|c|c|c|}
\hline Model Id & $\begin{array}{c}\text { Leudiking-Piret Model For Ethanol } \\
\text { Formation }\end{array}$ & $\begin{array}{l}\text { Leudeking-Piret Model For } \\
\text { Substrate Consumption }\end{array}$ \\
\hline Model Equation & $\begin{array}{c}\mathrm{Y}= \\
\mathrm{Y}^{*}\left(\left(4.6^{*} 6.2652^{*} \exp \left(0.04216^{*}(\mathrm{x}-\right.\right.\right. \\
\mathrm{t})) /(6.2652-4.6+ \\
\left.4.6^{*} \exp \left(0.04216^{*}(\mathrm{x}-\mathrm{t})\right)\right)- \\
\left(4.6^{*} 6.2652^{*} \exp (-\right. \\
\left.0.04216^{*} \mathrm{t}\right) /(6.2652-4.6+ \\
\left.\left.\left.\left.4.6^{*} \exp \left(-0.04216^{*} \mathrm{t}\right)\right)\right)\right)\right)\end{array}$ & $\begin{array}{c}Y=99.71604- \\
(4.6 / Y s)^{*}\left(\left(\exp \left(0.04216^{*} \mathrm{x}\right) /(1-\right.\right. \\
\left.(4.6 / 6.2652) *\left(1-\exp \left(0.04216^{*} \mathrm{x}\right)\right)\right)- \\
1))-\left(\mathrm{m}^{*} 6.2652 / 0.04216\right) * \operatorname{Ln}(1- \\
\left.(5 / 6.2652)^{*}\left(1-\exp \left(0.04216^{*} \mathrm{x}\right)\right)\right)\end{array}$ \\
\hline $\mathrm{R}^{2}$ Value & 0.91125(ESTIMATED) & 0.98617(ESTIMATED) \\
\hline Adjusted $\mathrm{R}^{2}$ Value & 0.89857 (ESTIMATED) & 0.9842 (ESTIMATED) \\
\hline \multirow[t]{2}{*}{ Model coefficients } & $Y=45.72092$ & $\mathrm{Yx} / \mathrm{s}(\mathrm{g} / \mathrm{g})=0.18292$ \\
\hline & $\mathrm{T}=-35.38716$ & $\mathrm{M}(\mathrm{g} / \mathrm{ghr})=0.008171$ \\
\hline
\end{tabular}

\section{Conclusion}

The processes involved in the production of ethanol from sugarcane juice are not complex ones when compared to other methods of alcohol production. The production is feasible due to the availability of the basic raw material which is sugarcane stem. Sugar cane stem contains an appreciable amount of sugar which makes the conversion into alcohol a success. The kinetic parameters necessary for its production through fermentation have been obtained in the developed mode. This study has also shown that immobilization of cell increases the yield. Sugarcane juice has thus been proven to be a viable best raw material for the production of ethanol.

\section{Compliance with ethical standards}

\section{Acknowledgments}

The authors would love to acknowledge the immense contribution of late Prof. C.C. Opara at the initial stage of this work. We also like to thank Mr. C.C. Oko for his assistance during the course of the laboratory experiments. 


\section{Disclosure of conflict of interest}

There is no conflict of interest.

\section{References}

[1] Ogbonna, J.C., Mashima, H., Tanaka, H.: Scale up of fuel ethanol production from sugar beet juice using loofa sponge immobilized bioreactor. Bioresour. Technol. ,2001; 76(1): 1-8.

[2] Abalaka, J.A. and Opara, C.C. Immobilization of whole cell for fermentation. Nigerian food journal, 1990; 8:67-77.

[3] Amenaghawon N.A, Okieimen C.O, Ogbeide S.E "Kinetic Modelling of Ethanol Inhibition during Alcohol fermentation of Corn Stover using Saccharomyces Cerevisiae", International Journal of Engineering Research and Applications (IJERA) , 2012; 2:798-803.

[4] Bloyd, C.N.: An Update on Ethanol Production and Utilization in Thailand. Pacific Northwest National Laboratory (PNNL), Richland, 2009.

[5] GarcÃa-MartÃnez, T., Moreno, J., Mauricio, J.C. \& Peinado, R., Natural sweet wine production by repeated use of yeast cells immobilized on Penicillium chrysogenum. LWT - Food Science and Technology, 2015; 61:503-509.

[6] Attkinson, B., Cunningham, J.D. and Pinches, A. (1984). Biomass hold-ups and overall rates of substrate (glucose) uptake of support particles containing a mixed microbial culture. Chem. Eng. Res. Dev. 62: 1186-1188.

[7] Blackburn, F. 'Sugar-cane'. Longman, New York, 1984.

[8] Ruter, P. Molasses utilization. Agricultural Services Bulletin. No. 25 Food and Agricultural Organization of the United Nations, Rome, Italy, 1975.

[9] Lehtonen, M., and Suomalainen, H. Rum. In "Alcoholic beverages” (Rose, A.H.ed.), Academic Press, London, 1977:595-633.

[10] Jones, L. and Scard, F, (1921). “The manufacture of Cane Sugar”. Duckworth \& Co. Second edition, USA.

[11] Kurtzman CP "Molecular taxonomy of the yeasts". Yeast, 1994;10;(13):1727-1740.

[12] Legras JL, Merdinoglu D, Cornuet J-M, Karst F. "Bread, beer and wine: Saccharomyces cerevisiae diversity reflects human history", chand publisher, India, 2007.

[13] Balasubramanian MK, Bi E, Glotzer M. "Comparative analysis of cytokinesis in budding yeast, fission yeast and animal cells" chand publisher, india, 2004.

[14] Battcock, M; Azam-Ali, S. Fermented Frutis and Vegetables. A Global Perspective. United Nations Rome Fao Agricultural Services Bulletin, 1998, 10-15.

[15] Fellows P. and A. Hampton 'Small-scale food processing - A guide for appropriate equipment' Intermediate technology Publications, Wiley, New York, 2000.

[16] Sitanggang A.B., H.S. Wu, S.S. Wang, J.C.W. Lan Fermentation Strategies: Nutritional Requirements, Yuan Ze University press, Taiwan, 2010.

[17] Zeynep Balci, Ural Akbulut,Levent Toppare, Selmiye Alkan, UfukBak and Yusuf Yagci, Immobilization of Yeast Cells in Several Conducting Polymer Matrices. J. Macromol. Sci.—pure appl. Chem., 2002;a39(3):183-197.

[18] Mayuri, K. Kulkarni, Pallavi T. Kininge, Nitin V. Ghasghase, Priya R. Mathapati and Sunil S. Joshi. (2011), Effect of additives on alcohol production and Kinetic studies of s.cerevisiae for sugar cane wine production. International Journal of Advanced Biotechnology and Research, 2011; 2(1):154-158.

[19] Durand, G. and Navano, J.M. Immobilized microbial cells, Process Biochem. , 1978; 13: 14-22.

[20] Leudenking, R and Piret, E.L. "A kinetic study of the Lactic acid fermentation batch process at controlled pH". Journal of Biochem. Microbiol.Tech.Engrng., 1959;1(14):393

[21] Chang, Raymond Physical Chemistry for the Biosciences. Sansalito, CA: University Science, 2005:363-371.

[22] Menten, L.; Michaelis, M.I. "Die Kinetik der Invertinwirkung", Biochem Z ,1913;49:333-369.

[23] Lineweaver, $\mathrm{H}$ and Burk, D. "The Determination of Enzyme Dissociation Constants". Journal of the American Chemical Society , 1934;56(3): 658-666. 
Global Journal of Engineering and Technology Advances, 2021, 07(01), 124-136

[24] Opara, C.C. "Biochemical and Microbiological Engineering", Chijioke Consultant publication. Ikenegbu, Owerri, 2002:144-146.

[25] Oghome, P.I., Kamalu, C.I.O. Kinetics Of Ethanol Production From Nypa Palm (Mangroves Palm) Through Fermentation Process International Journal of Engineering Research and Applications, 2012; 2:539-549. 